University of Nebraska - Lincoln

DigitalCommons@University of Nebraska - Lincoln

1998

Relationship of Gypsy Moth (Lepidoptera: Lymantriidae) Egg Mass Age to Persistence and Color, and an Evaluation of Two Methods to Distinguish New and Old Egg Masses

Kevin W. Thorpe

Insect Biocontrol Laboratory, Usda-Ars, Building 306, Barc-East, Beltsville, Md 20705

Follow this and additional works at: https://digitalcommons.unl.edu/entomologyother

Part of the Entomology Commons

Thorpe, Kevin W., "Relationship of Gypsy Moth (Lepidoptera: Lymantriidae) Egg Mass Age to Persistence and Color, and an Evaluation of Two Methods to Distinguish New and Old Egg Masses" (1998).

Entomology Papers from Other Sources. 104.

https://digitalcommons.unl.edu/entomologyother/104

This Article is brought to you for free and open access by the Entomology Collections, Miscellaneous at DigitalCommons@University of Nebraska - Lincoln. It has been accepted for inclusion in Entomology Papers from Other Sources by an authorized administrator of DigitalCommons@University of Nebraska - Lincoln. 


\title{
Relationship of Gypsy Moth (Lepidoptera: Lymantriidae) Egg Mass Age to Persistence and Color, and an Evaluation of Two Methods to Distinguish New and Old Egg Masses
}

\author{
KEVIN W. THORPE
}

Insect Biocontrol Laboratory, USDA-ARS, Building 306, BARC-East, Beltsville, MD 20705

\begin{abstract}
Environ. Entomol. 27(6): 1452-1462 (1998)
ABSTRACT It is necessary to distinguish new and old gypsy moth, Lymantria dispar (L.), egg masses when conducting gypsy moth population surveys. Egg masses within reach from the ground are touched to determine if they contain unhatched eggs and thus are considered new. The following 2 methods are used for egg masses not within reach: (1) visual discrimination between new and old egg masses or (2) by calculating the percentage of new egg masses at ground level and using this value to adjust counts of all egg masses not within reach. To evaluate these methods, egg-mass persistence and color between generations, the percentage of new and old egg masses at ground level and in the canopy, the ability of observers to visually distinguish new and old egg masses, and the effect of errors on the accuracy of estimates of the percentage of new egg masses was examined. Fifty-five percent of exposed new egg masses studied were still at least $25 \%$ intact at the time of the following year's egg-mass survey. However, the color of the egg masses was markedly lighter, providing a mechanism for visually distinguishing new and old egg masses. When egg masses are visually distinguished as new or old with an error rate $>0$, the resulting estimate of the percent new egg masses is usually biased. The magnitude of the bias varies with the rate of error and the actual percentage of new egg masses in the population, and can result in serious reductions in the accuracy of these estimates. In a field evaluation, new egg masses were incorrectly classified as old $16 \%$ of the time and old egg masses were incorrectly classified as new $16 \%$ of the time. Because it is unbiased, use of the ratio method to estimate the percentage of new egg masses is recommended whenever 10 or more egg masses are within reach from the ground.
\end{abstract}

KEY WORDS Lymantria dispar, egg mass, sampling, color, persistence

IN MOST GYPSY moth, Lymantria dispar (L.), management programs, the decision to conduct suppression activities is based on estimates of overwintering eggmass population density (Ravlin et al. 1987, Ravlin 1991). All egg mass survey methods that have been developed for gypsy moth, including timed walks (Eggen and Abrahamson 1983), fixed-and-variableradius plot surveys (Wilson and Fontaine 1978), fixedradius plot surveys (Kolodny-Hirsch 1986), and binomial sampling plans (Carter and Ravlin 1995), depend on the ability to distinguish new egg masses from those remaining from previous seasons. Researchers and workers have identified many factors that may contribute to high variability associated with egg-mass surveys, including weather conditions, tree species (Wilson et al. 1981), presence or absence of foliage (Carter et al. 1994), proximity to forest edges (Bellinger et al. 1989), presence of artificial objects (Campbell et al. 1976, Skaller 1985, Thorpe and Ridgway 1992), and inaccurate determinations of new and old egg masses (Wilson et al. 1981). The purpose of this

This article reports the results of research only. Mention of a proprietary product does not constitute an endorsement or a recommendation for its use by USDA. study is to address the problem of distinguishing new and old egg masses.

Two guides to operational gypsy moth egg-mass sampling have been issued by the USDA Forest Service. The 1st, which is based on fixed-and-variableradius plot surveys, recommends that workers distinguish new and old egg masses by touch when they are within reach from the ground or visually when they are out of reach (Wilson and Fontaine 1978). The 2nd, which is based on fixed-radius plot surveys, recommends that a ratio of new to old egg masses be determined by touching a sample of egg masses within reach, and that this ratio then be used to correct counts of egg masses that are out of reach (Liebhold et al. 1994). These 2 methods will hereafter be referred to as the "visual method" and the "ratio method," respectively. Informal inquiries by the author to state and county gypsy moth managers indicated that both approaches are used operationally to some extent. Logistic advantages of the visual method are that it does not require additional calculations that may be subject to mathematical errors and does not require the presence of egg masses within reach from the ground. Disadvantages are that it is subjective and the procedure and technique cannot be concisely de- 
scribed in a manual, but rather must be learned through training and practice.

The objective of this study was to provide information that could be used by gypsy moth managers to make informed decisions about which method to use in their programs. Data were collected on gypsy moth egg-mass persistence and color as they age, differences in the percentage of new and old egg masses at ground level and in the canopy, the distribution of new and old egg masses through time and space at 1 location, and the ability of workers to visually distinguish new and old egg masses. An analysis of the expected precision and accuracy of each method, and a recommendation for choosing between the 2 methods, is given.

\section{Materials and Methods}

Egg-Mass Persistence and Color. Four sites were selected that contained relatively high numbers of both new and old gypsy moth egg masses. Two of the sites were located at the Marine Corps Combat Development Command, Quantico, VA, 1 was located at the Beltsville Agricultural Research Center (BARC) Beltsville, MD, and 1 was located on private land near Staples Corners, MD. The sites were from 2 to 7 ha in area, were composed primarily of hardwood species, and were $>50 \%$ oak (Quercus spp.). Initial egg-mass densities, measured according to Liebhold et al. (1994), ranged from 7,981-9,843/ha. During August 1991,100 new egg masses at each site that were within reach from the ground were assigned a unique number and tagged. Egg masses, which were selected haphazardly, were located primarily on oak, beech (Fagus grandifolia Ehrhart), and pine (Pinus spp.). To examine the effect of exposure on egg-mass persistence and color change, every 10th egg mass was covered with an opaque plastic flap ( 25 by $20 \mathrm{~cm}$ ) that was stapled to the tree only at the top so that it could be lifted to inspect the egg mass. Each egg mass was visited monthly for $8 \mathrm{mo}$, and again 14 and $21 \mathrm{mo}$ after oviposition. At each visit, the amount of each egg mass remaining was recorded in $10 \%$ increments. For subsequent analyses, egg masses were considered missing when $<25 \%$ of the egg mass remained. Egg-mass color on each visit was quantified by comparing the egg mass with the page from the Maximum Chroma, 40 Hue Nickerson Color Fan (Munsell Color, Baltimore, MD), which was determined to most closely approximate the color hue expressed by egg masses (Munsell Hue 7.5 YR). The page contains 7 colors ranging in value from 9 to 3 (light to dark). Each egg mass was assigned a color value in increments of 0.5 . The mean percentage of egg masses remaining and egg-mass color were calculated for each site.

Ground Versus Canopy. To determine the difference in the percentage of new and old egg masses at the ground versus the canopy level, a bucket truck was used to access egg masses in the canopies of trees at 2 woodlots in Talbot County, MD, in April 1993 (before egg hatch). More than 100 egg masses were touched at each level within each site to determine if they were new or old.

Comparison of Visual and Ratio Methods. To quantify rates of error that occur when visually distinguishing new and old egg masses, a test was conducted at BARC in 1992 where new egg mass density was $\approx 8,000 /$ ha and $\approx 56 \%$ of the egg masses were new. Three workers each viewed 100 egg masses through binoculars ( $7 \times$ magnification; $35 \mathrm{~mm}$ objective lens) at a distance of $12 \mathrm{~m}$ and wrote down their assessment of whether each egg mass was new or old. The egg mass was then touched to determine for certain whether it was new or old. These data were pooled across workers to determine the rates at which new egg masses were incorrectly classified as old ( $=e r-$ ror $_{n}$ ) and old egg masses were incorrectly classified as new $\left(=\right.$ error $\left._{o}\right)$. A chi-square test of independence (Zar 1974) was performed to determine if the 2 error rates were different.

The accuracy of estimates of the percentage of new egg masses given different rates of error $_{n}$ and error was determined from binomial probability theory using the equation.

$$
P_{\text {est }}=P_{n} \cdot\left(1-\text { error }_{n}\right)+P_{o} \cdot \text { error }_{o}
$$

where $P_{e s t}$ is the estimated proportion of new egg masses, $P_{n}$ and $P_{o}$ are the actual proportions of new and old egg masses, respectively, and error $_{n}$ and error $_{o}$ are as described above, expressed as proportions. A resampling approach (Naranjo and Hutchison 1997) was used to determine the variability associated with estimating the percentage of new egg masses given different error rates and actual proportions of new and old egg masses, and over a range of egg mass numbers. A computer program was written to simulate the estimation of the percentage of new egg masses using the visual method 1,000 times for each different combination of the above factors and over a range of 8-160 egg masses. A random number generator was used to model variability at the prescribed error rates. Confidence intervals and the proportion of estimates falling within $\pm 10 \%$ of the actual percentage of new egg mass values were calculated directly from the distribution of 1,000 resampled estimates.

The probability that an estimate of the percentage of new egg masses is within $\pm 10 \%$ of the correct value when using the ratio method was calculated directly from the binomial distribution of probabilities associated with different proportions of new and old egg masses at different sample sizes ranging from 5 to 160 (Zar 1974).

The accuracy of visual estimates of the percentage of new egg masses in the field was further evaluated by the following procedure performed in a woodlot in Talbot County, MD, in October 1992, in a woodlot in Queen Annes County, MD, in November 1993 and again at the same location in April 1994. All woodlots had high (>1,000 egg masses per hectare) egg-mass density, and the percentage of new egg masses ranged from 52 to 88 . A tree with 2 or more egg masses within reach from the ground was selected, and each of 3 experienced workers visually examined the egg 


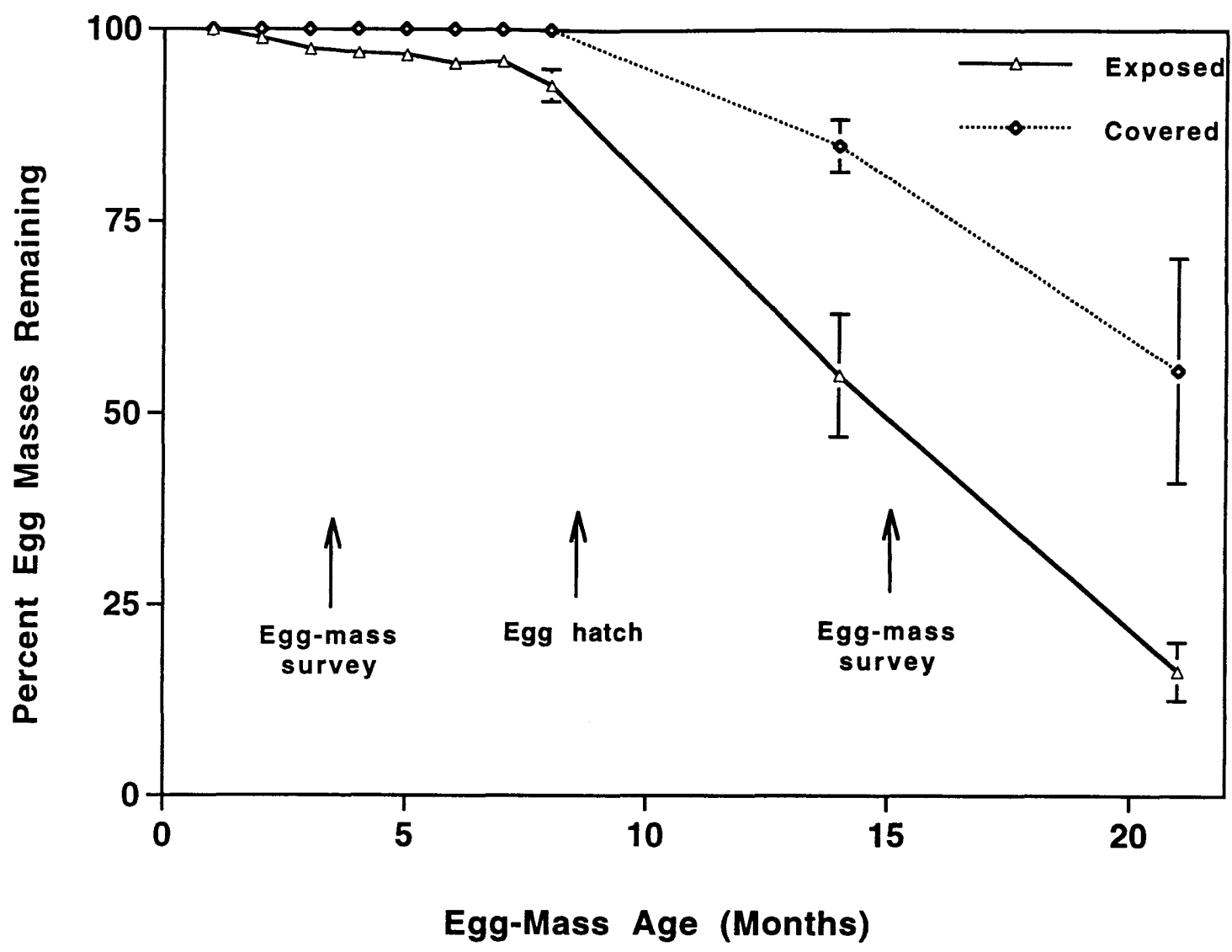

Fig. 1. Gypsy moth egg mass persistence through time for exposed and covered egg masses. Egg masses were considered missing when they were $<25 \%$ intact. Error bars represent standard errors of the mean at 4 sites.

masses through binoculars $(7 \times$ magnification; $35-\mathrm{mm}$ objective lens) at a distance of $\approx 15 \mathrm{~m}$ and recorded the number of egg masses that appeared new or old. After each worker had finished, the egg masses were touched to determine the actual number of new and old egg masses (Liebhold et al. 1994). This operation was performed 48 times at the Talbot County location, and 25 times at each visit to the Queen Annes County location.

Spatial and Temporal Distribution of Percent New Egg Masses. To examine the relationship between gypsy moth population density trends and the distribution of the percentage of new egg masses through time and space, records from 6 yr of gypsy moth egg-mass survey data at BARC were tabulated. These surveys were conducted every year from 1990 to 1995 by various private contractors. All egg mass surveys were conducted as $0.01 \mathrm{ha}(1 / 40$ th acre) fixed-radius plot surveys according to procedures described in Liebhold et al. (1994), which use the ratio method to calculate the percentage of new egg masses. The survey plots were distributed uniformly over the $\approx 1,159$ forested hectares of BARC. For the purposes of this analysis, BARC was divided into 3 geographically distinct sections, with section A located east of the Bal-
timore-Washington Parkway, section B located between U.S. Rt. 1 and the Parkway, and section C located west of U.S. Rt. 1. For the first 3 yr (1990 1992 ), $\approx 100$ surveys plots were placed in each of sections $\mathrm{A}$ and $\mathrm{B}$, and $\approx 30$ plots were placed in section C. Funding constraints reduced these numbers by $50 \%$ during the last 3 yr (1993-1995). All egg-mass survey data records included separate entries for new and old egg masses that could be touched from the ground and for all egg masses that were out of reach. The percentage of new egg masses was calculated from survey records for each section within each year. The standard deviation of each percentage was calculated using an equation appropriate for 2-stage sampling for percentage values (Cochran 1977):

\section{Standard deviation}

$$
=\sqrt{\left(\sum a_{i}^{2}-2 p \sum a_{i} m_{i}+p^{2} \sum m_{i}^{2}\right) /\left(n \bar{m}^{2}(n-1)\right)} \cdot 100,
$$

where $n=$ the number of plots, $m_{\mathrm{i}}=$ the total number of egg masses in the ith plot, $a_{\mathrm{i}}=$ the total number of new egg masses in the $i$ th plot, $P=$ the overall pro- 


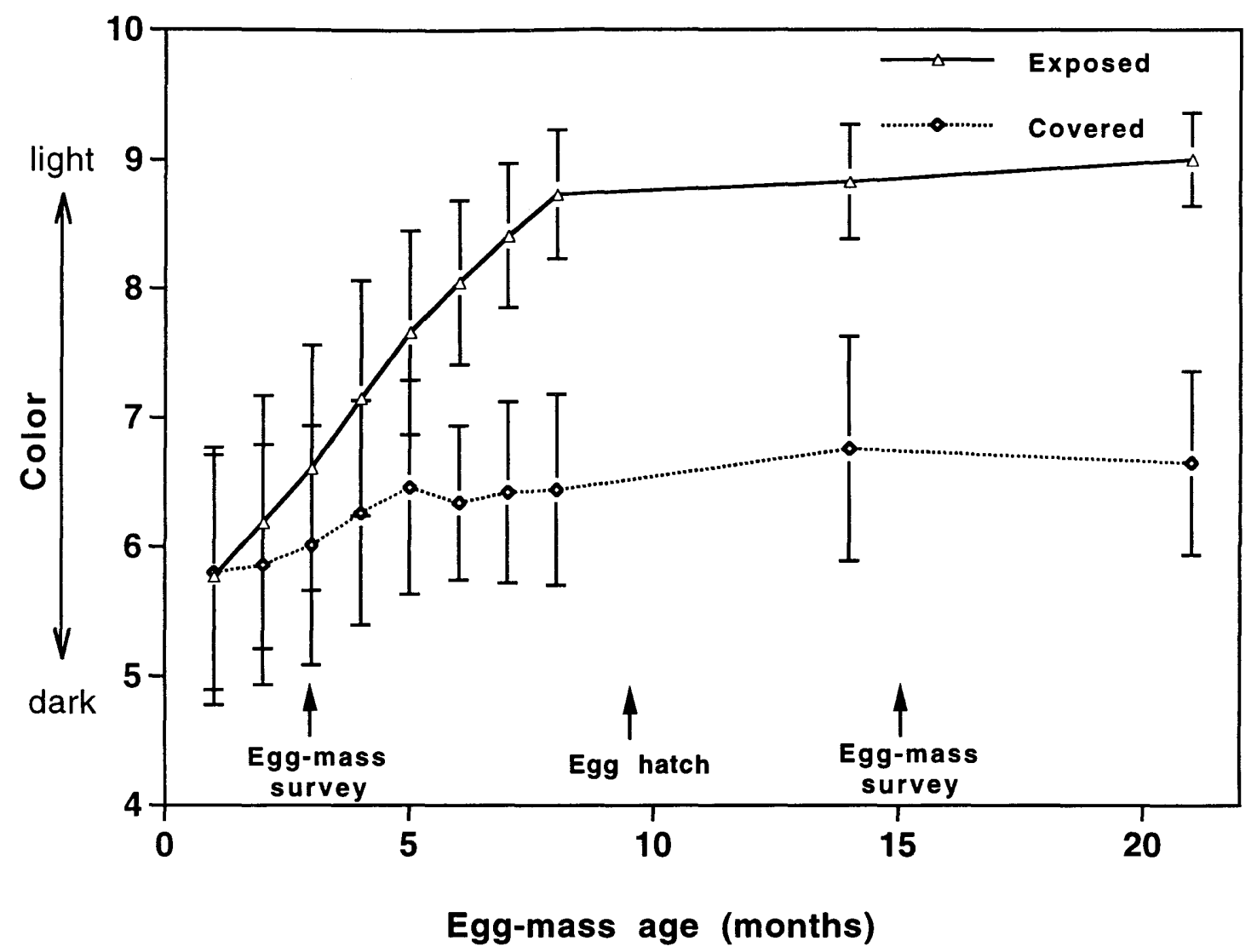

Fig. 2. Gypsy moth egg mass color through time for exposed and covered egg masses. Color is expressed in units of Munsell Color Value (see text). Error bars represent standard deviations of all observations.

portion of new egg masses in the section, and $\bar{m}=$ the average number of egg masses per plot $\left(=\Sigma m_{\mathrm{i}} / n\right)$.

\section{Results and Discussion}

Egg-Mass Persistence and Color. All covered egg masses persisted until they hatched in April (Fig. 1). At the time of the following year's egg-mass survey (14 mo after oviposition), $84.9 \%$ of the covered egg masses remained. At $21 \mathrm{mo}$ after oviposition, $55.6 \%$ of the covered egg masses remained. Although some of the exposed egg masses began to disappear immediately after oviposition, $92.8 \%$ remained at the time of egg hatch. By the time of the following year's egg-mass survey, $55.0 \%$ remained, and at $21 \mathrm{mo}$ after oviposition only $16.3 \%$ remained. In a study of gypsy moth eggmass predation in Connecticut, Cooper and Smith (1995) found that $18 \%$ of the egg masses in their study site were $<25 \%$ intact on 28 April. This is similar but somewhat higher than the disappearance rate reported here $(7.2 \%)$ for the same length of exposure. Cooper and Smith (1995) did not report egg-mass disappearance rates beyond the time of egg hatch. Data from the current study show that old egg masses persist, possibly in considerable numbers, depending on egg-mass density, into the period during which the following year's egg-mass surveys are conducted, and that some probably persist for yet another year.

Egg-mass color value 1 mo after oviposition averaged 5.8. Both covered and exposed egg masses became lighter through time, although the rate of change was much greater for exposed egg masses (Fig, 2). At the time of year that egg-mass surveys are typically conducted (September), covered egg masses had a mean color value of 6.0 and exposed egg masses had a mean value of 6.6. At the time of egg hatch, egg-mass color values averaged 6.5 for covered and 8.7 for exposed egg masses. At the time of the following year's egg-mass surveys, egg-mass color values averaged 6.7 for covered and 8.8 for exposed egg masses. Using the standard deviations calculated from the pooled data, it

Table 1. Numbers of new and old gypsy moth egg masses and percentage of new egg masses deternined at the ground and canopy levels

\begin{tabular}{lcrcrrrr}
\hline \hline \multirow{2}{*}{ Site } & \multicolumn{4}{c}{ Ground } & & \multicolumn{3}{c}{ Canopy } \\
\cline { 2 - 4 } \cline { 6 - 8 } & New & Old & \% new & New & Old & \% new \\
\hline Vienna & 535 & 45 & $92.2 \pm 2.5$ & 350 & 30 & $92.1 \pm 3.4$ \\
Bozman & 195 & 124 & $61.1 \pm 9.2$ & & 120 & 141 & $46.0 \pm 11.7$ \\
\hline
\end{tabular}

Percent values are means $\pm \mathrm{SD}$ of 7 trees. 

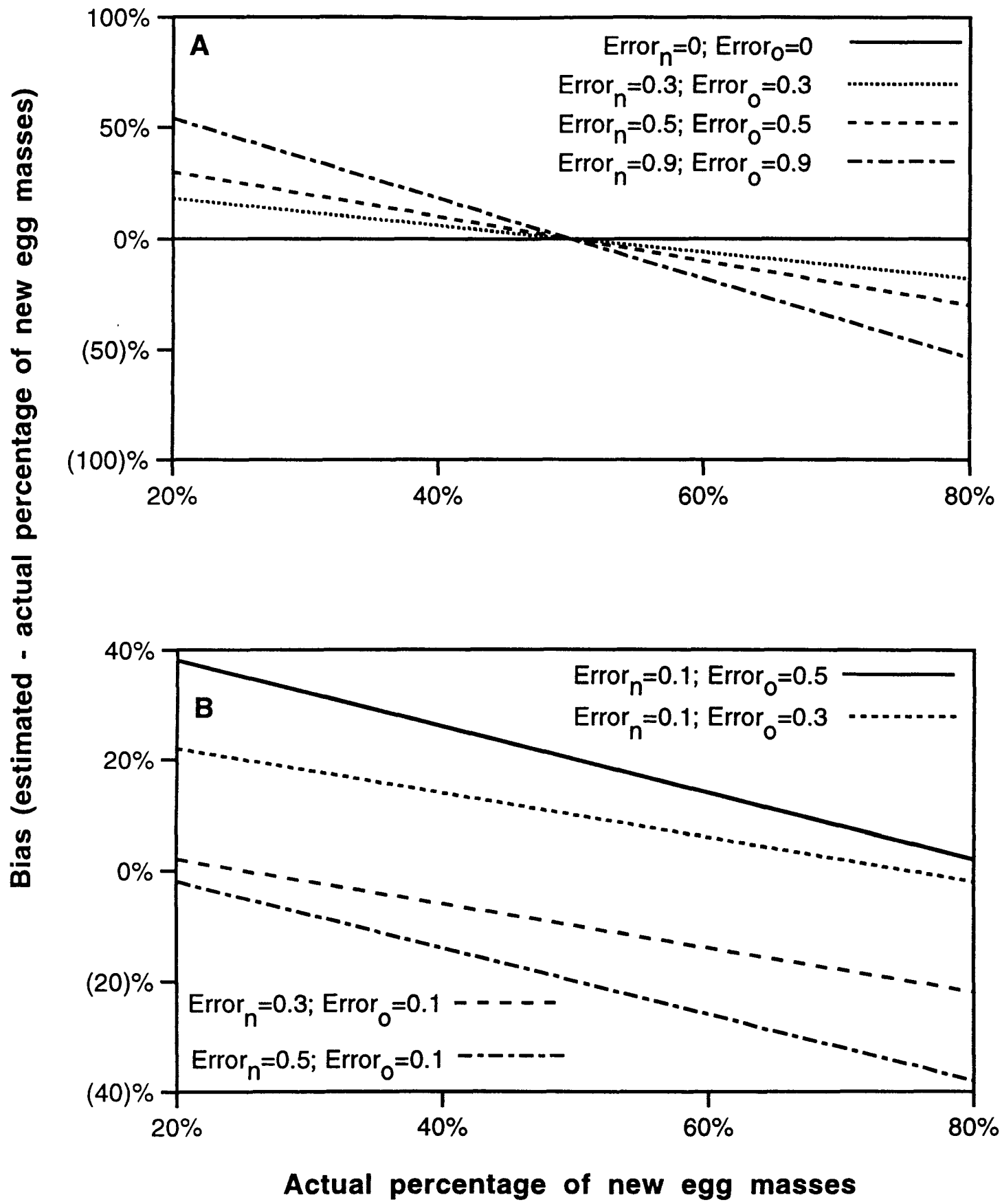

Fig. 3. Effect of different rates of error ${ }_{n}$ (the incorrect classification of new egg masses as old) and error (the incorrect classification of old egg masses as new) on bias in estimates of the percentage of new egg masses using the visual method

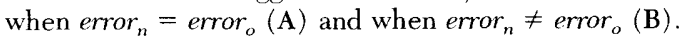

is possible to calculate the proportion of new and old egg masses with color values greater or less than any particular value based on the normal probability distribution. For exposed egg masses at 14 mo (the time at which egg mass surveys are normally conducted), when old egg masses are at least 14 mo old and new egg masses are 2 mo old, and using a color value of 8 as a threshold for classifying egg masses as new or old, the probability of incorrectly classifying new egg masses as old based on color alone is 0.072 and the probability of incorrectly classifying old egg masses as new is 0.028 . Therefore, given the color distribution among 
new and old egg masses found in this study, it should be possible to visually distinguish between new and old exposed egg masses based on color alone with $>90 \%$ accuracy. However, as shown in the next section, actual measured error rates $(\approx 32 \%)$ are greater than this value, perhaps because not all egg masses are exposed or workers are relying on visual information other than color that may not be as reliable.

Ground Versus Canopy. The number of new and old egg masses found at the ground and canopy levels at 2 woodlots is shown in Table 1 . At the Vienna site, the percentage of new egg masses was $>90 \%$ and was nearly identical at the ground and canopy levels. However, at the Bozman site, where the percentage of new egg masses was near $50 \%$, the ratio of new and old egg masses differed by $15 \%$ between the ground and canopy levels. Although the number of sites is too few to draw meaningful statistical inferences, these data suggest that, at least in some cases, the practice of determining the percentage of new egg masses at ground level and then applying that percentage to egg masses that are out of reach from the ground may lead to inaccurate estimates of gypsy moth density.

Accuracy and Precision of Estimates. If egg masses could be classified visually as new or old without error, the visual method would always provide estimates of the percentage of new egg masses with $100 \%$ accuracy. However, it is not possible to visually classify egg masses as new or old without error. As shown in Fig. 3 , estimates of the percentage of new egg masses generated with a nonzero error rate are usually biased. For any given error rate, the magnitude of the bias varies with the actual percentage of new egg masses. When error $_{n}=$ error $_{o}$, estimates are unbiased when the actual percent new egg masses is 50 regardless of the magnitude of the error rates. As the actual percentage of new egg masses increases or decreases from 50 , the magnitude of the bias increases as the sum of error $_{n}$ and error $_{o}$ increases.

The effect of bias on the accuracy of estimates of the percentage of new egg masses over a range of egg mass numbers when using the visual method is shown in Fig. 4 . In these graphs, $95 \%$ confidence bands around the estimated percentage of new egg mass values (error $_{n}=$ error $_{o}=0.3$ ) are shown when the actual percentage of new egg masses is 25,50 , and 75 . When the actual percentage of new egg masses is 50 , the confidence band narrows around this value as the number of egg masses increases because the estimate is unbiased. However, when the actual percentage of new egg masses is 25 or 75 , the confidence bands narrow around incorrect (=biased) values. Fig. 5 shows the probability of estimating within $\pm 10 \%$ of the actual percentage of new egg masses for the visual method at different error rates for which error ${ }_{n}=$ error $_{o}$. When the actual percentage of new egg masses is 50 , all estimates are unbiased and the probability of the estimate being within $\pm 10 \%$ of the actual value approaches 1 regardless of the error rate. The probability of estimating within $\pm 10 \%$ of the correct value is also shown for estimates using the ratio method. With the ratio method, egg masses are classified as new or old
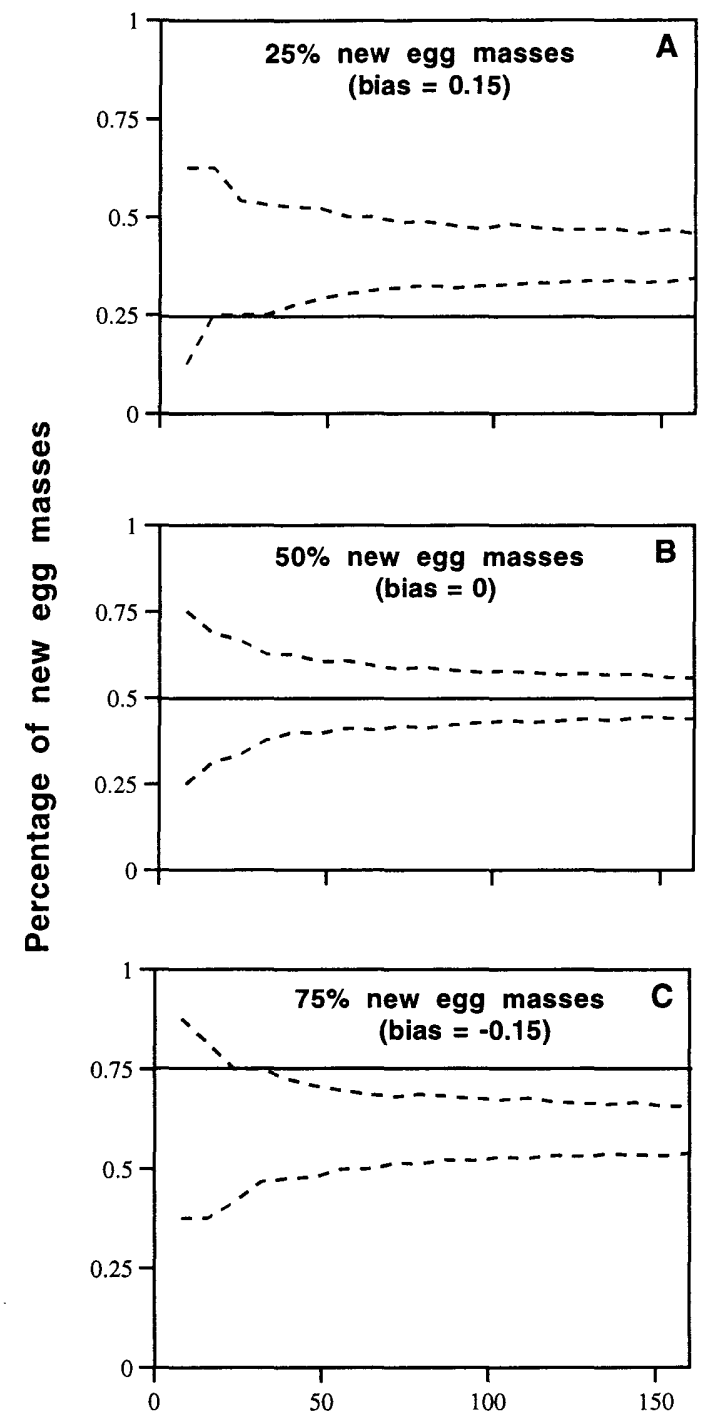

No. of egg masses

Fig. 4. Confidence bands (95\%) around estimates of the percentage of new egg masses using the visual method at 25 (A), 50 (B), and 75\% (C) actual new egg masses when error $_{n}$ $=$ error $_{o}=0.3$.

by touch and without error. The estimated percentage of new egg masses is obtained by taking a sample of egg masses (=those that can be touched) and using the proportion of new egg masses in the sample as an estimate of the overall proportion of new egg masses. Assuming that the proportion of egg masses within reach from the ground is the same as that of the egg masses that are out of reach, estimates using this method are unbiased. The probability of estimating the percentage of new egg masses within $\pm 10 \%$ of the actual value using the ratio method is determined entirely by sampling error which follows the binomial distribution. In reading the graphs in this figure, the 


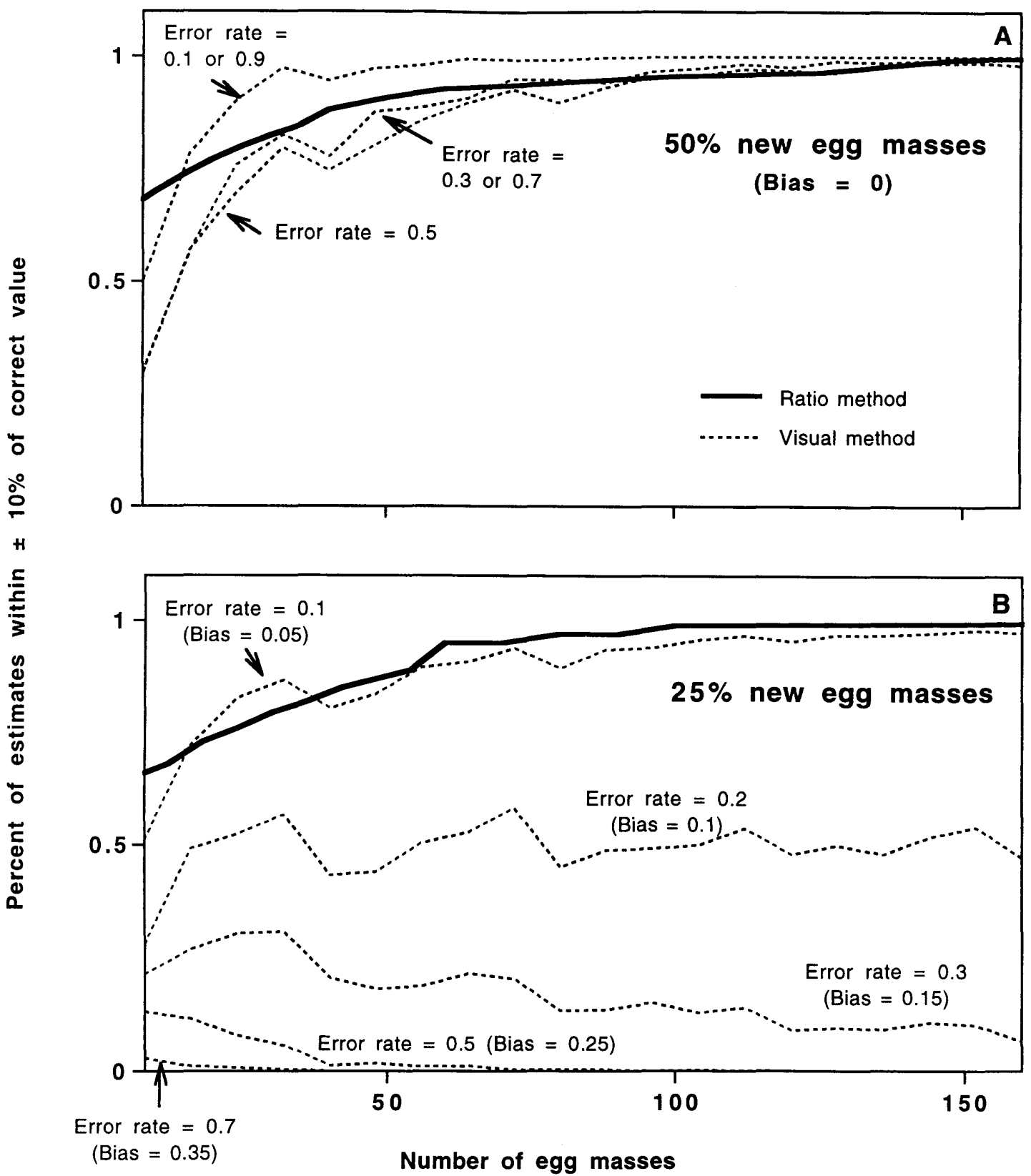

Fig. 5. Effect of different rates of error when error ${ }_{n}=$ error $_{o}$ using the ratio and visual methods on the expected accuracy of estimates of the percentage of new egg masses at 50 (A) and $25 \%$ (B) actual new egg masses.

number of egg masses upon which the estimates are based is not the same for the ratio and visual methods. For the visual method, the number of egg masses is the total number of egg masses encountered at the sampling point. For the ratio method, the number of egg masses is the number of egg masses sampled (=touched). For example, if at a particular site there are 100 egg masses and $10 \%$ of these are within reach from the ground, the probability value for the ratio method should be read at a value of $10 \mathrm{egg}$ masses (the number available for touching) and the visual method probability should be read at a value of 100 egg masses (the number available for viewing). As the actual percent new egg masses deviates from 50 , the estimates obtained using the visual method become increasingly biased, leading to a decrease in the probability of obtaining estimates within $\pm 10 \%$ of the actual percent new egg mass value. At an error rate of error $_{n}=$ error $_{o}=0.1$ the bias is small and the estimates are as good or slightly better than those obtained using 


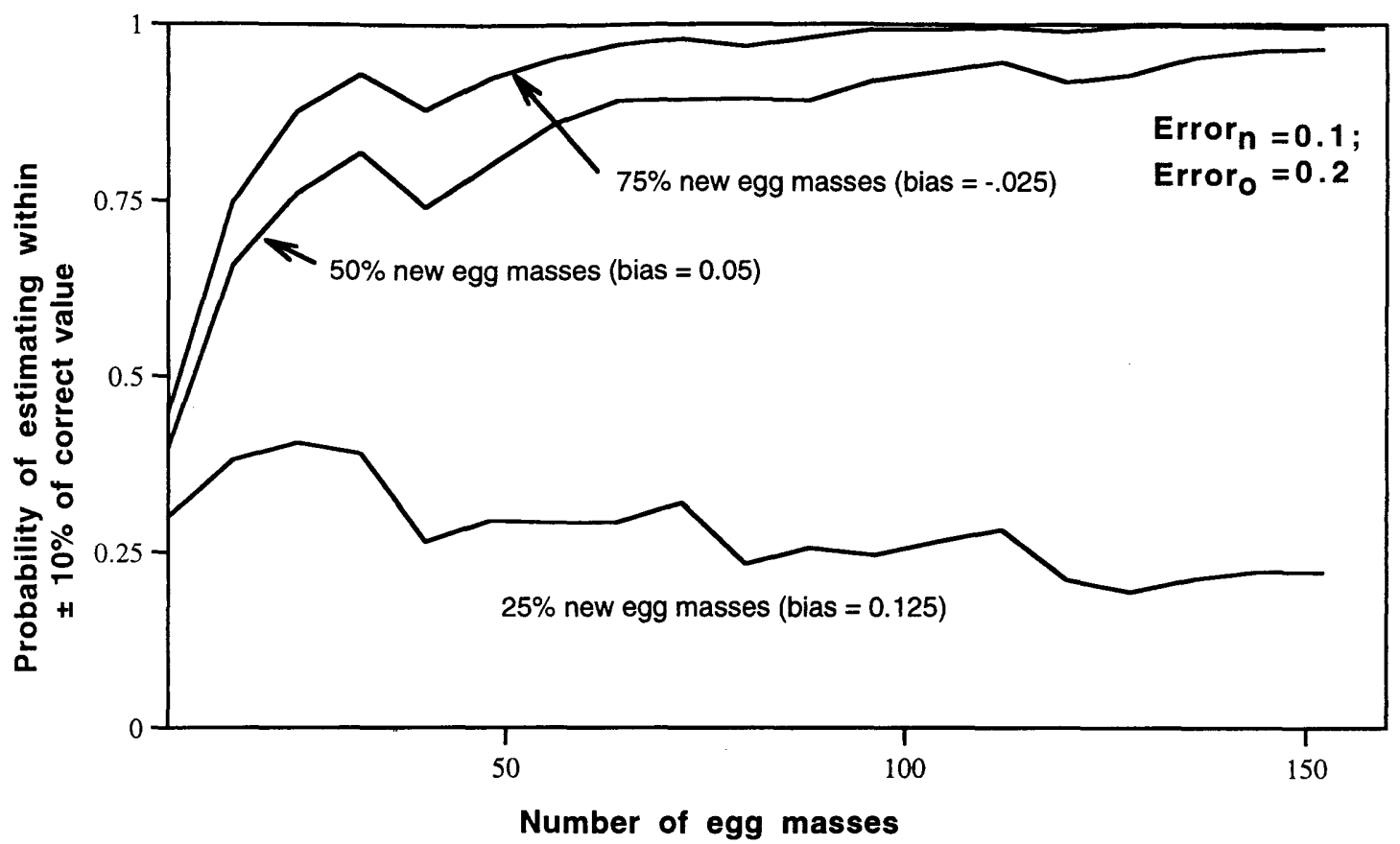

Fig. 6. Expected accuracy using the visual method of estimates of the percentage of new egg masses when error $_{n}=0.1$ and error $=0.2$ at 25,50 , and $75 \%$ actual new egg masses.

the ratio method. However, when the error rate increases to error $_{n}=$ error $_{o}=0.2$ or greater, the probability of estimating within $\pm 10 \%$ of the actual percentage of new egg masses is equal to or $<0.5$ regardless of the number of egg masses. This probability is well below that obtained using the ratio method even when the sample size is small.

Fig. 6 shows the reliability of estimates using the visual method when error ${ }_{n}$ and error ${ }_{o}$ are greater than zero and unequal. The probability of estimating within $\pm 10 \%$ of the actual percentage of new egg masses varies with the amount of bias, which can be estimated using equation 1 . With relatively low error rates $\left(\right.$ error $_{n}=0.1$; $_{\text {error }}=0.2$ ), the probability of correct estimates ranges from near 1 to $<0.5$, depending on the actual percentage of new egg masses.

Actual Error Rates in the Field. Of the 56 new and 44 old egg masses visually examined by each of 3 workers, $68.3 \%$ were correctly classified as either new or old. New egg masses were incorrectly classified as old $15.7 \%$ of the time (error ${ }_{n}$ ), and old egg masses were incorrectly classified as new $16.0 \%$ of the time (error ${ }_{o}$ ). A chi-square test of independence indicated that the 2 error rates were not significantly different $\left(\chi^{2}=2.4\right.$, $\mathrm{df}=1, P=0.12$ ).

Results of the 2 nd test to quantify the ability of workers to visually distinguish new and old gypsy moth egg masses are shown in Table 2 . At the Talbot County site, $51.5 \%$ of the egg masses were new. Three workers provided visual estimates that ranged from 48.4 to $53.8 \%$ new. At the Queen Annes County site in November $1993,83.2 \%$ of the egg masses were new, and the workers provided visual estimates that ranged from 71.1 to $75.1 \%$. At the same site the next spring, the percentage of new egg masses was 88.1 , and the same workers provided visual estimates that ranged from 59.5 to $84.3 \%$. Averaged over the 3 workers, the visual estimates of the percentage of new egg masses was nearly the same as the actual percentage of new egg masses at the Talbot County site, and from 9.8 to $13.4 \%$

Table 2. Visual estimates by three workers of the percentage of new gypsy moth egg masses compared with the actual percentage of new egg masses

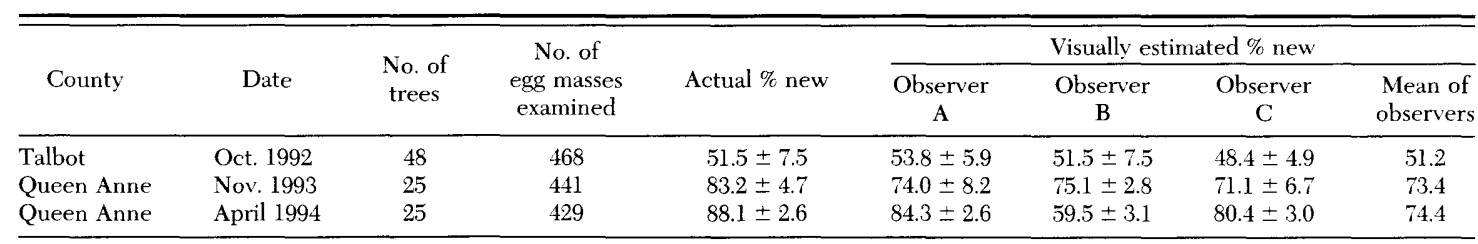

Values are percentages \pm SD; workers viewed egg masses through binoculars at a distance of $15 \mathrm{~m}$; actual percentages were calculated by touching the egg masses to determine if they were new or old. 


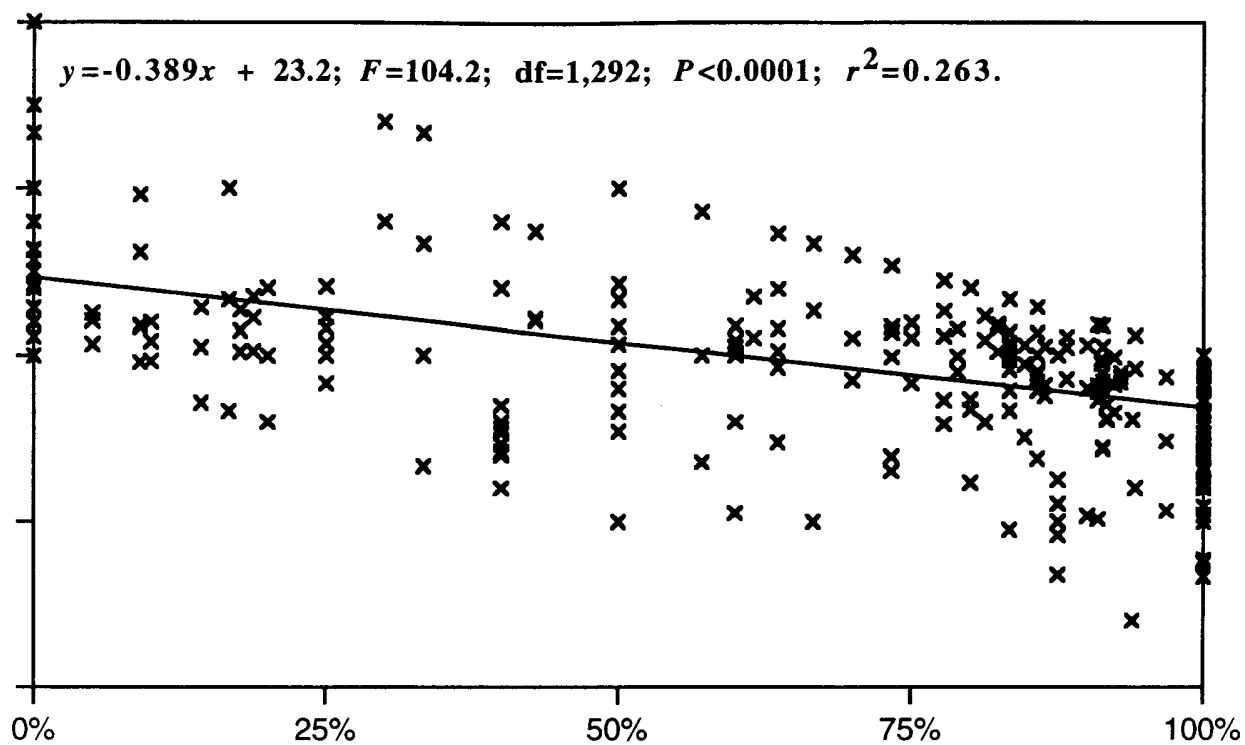

\section{Actual percentage of new egg masses}

Fig. 7. Effect of the actual percentage of new egg masses on bias (= estimated minus actual percent new egg masses) of estimates of the percentage of new egg masses by 3 workers on 3 occasions.

lower on the 2 occasions at the Queen Anne County site. The percentage values were estimated from 98 groups of egg masses, with groups ranging in size from 2 to 62 egg masses. Fig. 7 shows a plot of these data indicating the degree of bias versus the actual percentage of new egg masses. When the percentage of new egg masses is low, the estimated percentage of new egg masses tended to be too high. The percentage tended to be under-estimated when the actual percentage of new egg masses was high. These results agree with the amount of bias predicted by equation 1 given nonzero values of error ${ }_{n}$ or error ${ }_{o}$, or both.

This test of visual discrimination of new and old egg masses was conducted using only egg masses on tree boles. It is possible that these egg masses may have been more exposed than egg masses in the canopy and therefore may have lightened in color at a faster rate than those in the canopy. If so, it may be that visual discrimination of new and old egg masses would be less reliable for egg masses in the canopy than reported here for egg masses on boles. Also, lighting conditions are usually less favorable for viewing egg masses in the canopy than on boles, which could further reduce the accuracy of visual determinations of new and old egg masses in the canopy.

Spatial and Temporal Distribution of Percent New Egg Masses. The percentage of new egg masses, based on samples within reach from the ground, and the estimated egg-mass density, are shown for the 3 sections of BARC from 1990 to 1995 in Table 3. Gypsy

Table 3. Results of gypsy moth egg-mass surveys in three sections of the Beltsville Agricultural Research Center, Beltsville, MD 1991-1995

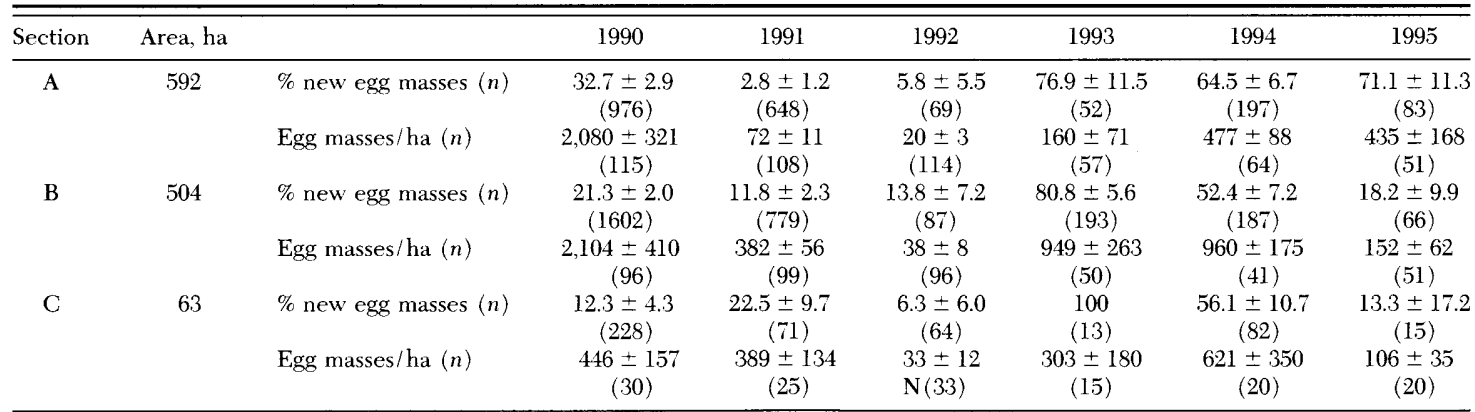

Values are mean $\pm 95 \% \mathrm{CI}$ (\% new egg masses) or mean \pm SEM (egg masses per hectare). $n$, number of egg masses touched (\% new egg masses) or number of egg-mass survey plots (egg masses per hectare). 
moth populations were at their highest levels in 1990 , with egg-mass densities ranging from 446 to $2,104 / \mathrm{ha}$. However, the percentage of new egg masses was low in all areas, indicating that the population was in decline. In 1991 and 1992, populations were low, with egg-mass densities ranging from 20 to $389 / \mathrm{ha}$, and with the percentage of new egg masses ranging from 2.8 to 22.5. In 1993, population density began to increase again, with egg-mass densities ranging from 160 to $949 /$ ha and the percentage of new egg masses from 76.9 to 100 . Population density remained high in 1994 and then again declined in 1995. In 1994, the percent new egg masses ranged from 52.4 to 64.5 . In 1995 , the percentage of new egg masses was high in section $\mathrm{A}$ (71.1\%) and low in sections B and C (18.2 and 13.3\%, respectively).

The data shown in Table 3 illustrate an important potential problem with the ratio method. The percentage of new egg masses was relatively consistent among the 3 sections for each year except 1995. In that year, section A had a much higher percentage of new egg masses than the other sections. When conducting an egg-mass survey, the manager must decide how broad of an area to use to calculate the percentage of new egg masses. The use of a percentage value based on all 3 sections pooled in 1995 would have led to inaccurate estimates of egg-mass density in each of the individual sections. However, dividing each of the sections into still smaller units would probably have resulted in a greater degree of inconsistency among units, especially because the sample sizes used to generate the percentage values would be much smaller.

When egg mass numbers are low, use of the ratio method may not be desirable because too few egg masses are within reach from the ground to provide a sufficient sample. In this case, the visual method should be used. However, unless new and old egg masses can be distinguished visually with little or no error, the estimates of the percentage of new egg masses obtained using this method will usually be biased. Depending on the magnitude of the errors and the actual percentage of new egg masses, the accuracy of estimates of percentage of new egg masses obtained using the visual method may be unacceptably low. Because the error rates of workers are unknown and probably vary with different situations, the accuracy of estimates obtained using the visual method are also unknown. In most cases, estimates obtained using the ratio method will be as good or better than those obtained using the visual method, even when the number of egg masses within reach from the ground is small. As error rates with the visual method increase, the reduction in the accuracy of estimates obtained using the visual method compared to the ratio method increases. At sample sizes of $<10$, the accuracy of estimates of the percentage of new egg masses using the ratio method is greatly reduced. Therefore, use of the ratio method to estimate the percentage of new egg masses is recommended whenever 10 or more egg masses can be found within reach from the ground When fewer egg masses are within reach, the visual method should be used, with the understanding that the accuracy of the estimates may be quite low, depending on the rates of error and the actual percentage of new egg masses in the population.

\section{Acknowledgments}

I thank F. FitzMaurice, J. Leader, T. Mellon, M. Sandy, T. Sukontarak, P. Whatling, and L. Venables for assistance in conducting this study; A. Liebhold and M. Montgomery (USDA-FS) and L. Douglass (USDA, ARS) for reviewing an earlier version of the manuscript; Brady Tree Service for providing the bucket truck; and J. Giannico (Marine Corps Command Development Center, Quantico, VA). T. Badger (USDA-ARS), S. Velo (Bozman, MD), and E. Willy (Vienna, MD) for permission to conduct research at their locations.

\section{References Cited}

Bellinger, R. G., F. W. Ravlin, and M. L. McManus. 1989. Forest edge effects and their influence on gypsy moth (Lepidoptera: Lymantriidae) egg mass distribution. Environ. Entomol. 18: 840-843.

Campbell, R. W., M. G. Miller, E. J. Duda, C. E. Biazak, and R. J. Sloan. 1976. Man's activities and subsequent gypsy moth egg-mass density along the forest edge. Environ. Entomol. 5: 273-276.

Carter, J. L., and F. W. Ravlin. 1995. Evaluation of binomial egg mass sampling plans for low density gypsy moth populations in continuously forested habitats. J. Econ. Entomol. 88: 890-896.

Carter, J. L., F. W. Ravlin, D. R. Gray, M. R. Carter, and C. W. Coakley. 1994. Foliage presence and absence effect on gypsy moth (Lepidoptera: Lymantriidae) egg mass sample counts and the probability of exceeding action thresholds with foliage present. J. Econ. Entomol. 87: 1004-1007.

Cochran, W. G. 1977. Sampling techniques. Wiley, New York.

Cooper, R. J., and H. R. Smith. 1995. Predation on gypsy moth (Lepidoptera: Lymantriidae) egg masses by birds. Environ. Entomol. 24: 571-575.

Eggen, D. A., and L. P. Abrahamson. 1983. Estimating gypsy moth egg mass densities. School of Forestry ESF 83-002. College of Environmental Science and Forestry, State University of New York, Syracuse, NY.

Kolodny-Hirsch, D. M. 1986. Evaluation of methods for sampling gypsy moth (Lepidoptera: Lymantriidae) egg mass populations and development of sequential sampling plans. Environ. Entomol. 15: 122-127.

Liebhold, A., K. Thorpe, J. Ghent, and D. B. Lyons. 1994. Gypsy moth egg mass sampling for decision-making: a users' guide. U.S. Dep. Agric. For. Serv. NA-TP-04-94.

Naranjo S. E., and W. D. Hutchison. 1997. Validation of arthropod sampling plans using a resampling approach: software and analysis. Am. Entomol. 43: 48-57.

Ravlin, F. W., R. G. Bellinger, and E. A. Roberts. 1987. Gypsy moth management programs in the United States: status, evaluation, and recommendations. Bull. Entomol. Soc. Am. 33: 90-98.

Ravlin, F. W. 1991. Development of monitoring and decision-support systems for integrated pest management of forest defoliators in North America. For. Ecol. Manage. 39: 3-13.

Skaller, M. P. 1985. Patterns in the distribution of gypsy moth (Lymantria dispar) (Lepidoptera: Lymantriidae) egg masses over an 11-year population cycle. Environ. Entomol. 14: 106-117. 
Thorpe, K. W., and R. L. Ridgway. 1992. Gypsy moth (Lepidoptera: Lymantriidae) egg mass distribution and sampling in a residential setting. Environ. Entomol. 21: 722730.

Wilson, R. W., Jr., and G. A. Fontaine. 1978. Gypsy moth egg mass sampling with fixed-and-variable-radius plots. U.S. Dep. Agric. Handb. 523.

Wilson, R. W., S. M. Ivanowsky, and R. L. Talerico. 1981. Direct evaluation, pp. 34-38. In C. C. Doane and M. L.
McManus [eds.], The gypsy moth: research toward integrated pest management. U.S. Dep. Agric. For. Serv. Tech. Bull. 1584 .

Zar, J. H. 1974. Biostatistical analysis. Prentice-Hall, Englewood Cliffs, NJ.

Received for publication 31 October 1997; accepted 20 July 1998. 